\title{
Genome-scale portrait and evolutionary significance of human-specific core promoter tri- and tetranucleotide short tandem repeats
}

\author{
N. Nazaripanah ${ }^{1}$, F. Adelirad ${ }^{1}$, A. Delbari ${ }^{1}$, R. Sahaf ${ }^{1}$, T. Abbasi-Asl $^{2}$ and M. Ohadi ${ }^{1 *}$
}

\begin{abstract}
Background: While there is an ongoing trend to identify single nucleotide substitutions (SNSs) that are linked to inter/intra-species differences and disease phenotypes, short tandem repeats (STRs)/microsatellites may be of equal (if not more) importance in the above processes. Genes that contain STRs in their promoters have higher expression divergence compared to genes with fixed or no STRs in the gene promoters. In line with the above, recent reports indicate a role of repetitive sequences in the rise of young transcription start sites (TSSs) in human evolution.
\end{abstract}

Results: Following a comparative genomics study of all human protein-coding genes annotated in the GeneCards database, here we provide a genome-scale portrait of human-specific short- and medium-size ( $\geq 3$-repeats) tri- and tetranucleotide STRs and STR motifs in the critical core promoter region between -120 and +1 to the TSS and evidence of skewing of this compartment in reference to the STRs that are not human-specific (Levene's test $p<0$. 001). Twenty-five percent and $26 \%$ enrichment of human-specific transcripts was detected in the tri and tetra human-specific compartments (mid- $p<0.00002$ and mid- $p<0.002$, respectively).

Conclusion: Our findings provide the first evidence of genome-scale skewing of STRs at a specific region of the human genome and a link between a number of these STRs and TSS selection/transcript specificity. The STRs and genes listed here may have a role in the evolution and development of characteristics and phenotypes that are unique to the human species.

Keywords: Short tandem repeat, Core promoter, Human-specific, Trinucleotide, Tetranucleotide

\section{Introduction}

Speciation and evolution are, at least in part, due to the plasticity (expansion or contraction) of short tandem repeats (STRs)/microsatellites, which can function as "tuning knobs" in response to the environment or other genes [1-3]. In line with the above, certain STRs are directionally expanded in the human species or co-occur identically in related taxa such as primates [4-8]. Genes that contain STRs in their promoters have higher expression divergence compared to genes with fixed or no

\footnotetext{
*Correspondence: mi.ohadi@uswr.ac.ir; ohadi.mina@yahoo.com 'Iranian Research Center on Aging, University of Social Welfare and Rehabilitation Sciences, Tehran, Iran

Full list of author information is available at the end of the article
}

STRs in the gene promoters [9]. Recent reports indicate a role of repetitive sequences in the rise of young transcription start sites (TSSs) in human evolution [10-12].

Preliminary data on the sequencing of a number of "exceptionally long" STRs ( $\geq 6$-repeats), which compose 1 $2 \%$ of all human core promoter STRs [3], support critical evolutionary adaptive roles for a number of these STRs. Human specificity of the predominant allele of the RIT2 core promoter STR in the human species, the presence of the shortest allele of this STR (5-repeat) in huntergatherer humans (BUSHMAN KB1: rs113265205), the lack of this allele in the agricultural modern humans (Genome Aggregation database: gnomad.broadinstitute. org), and its co-occurrence with schizophrenia provide the 
first indication of STR allele selection in humans [13]. A link between the CYTH4 core promoter STR (the longest tetranucleotide STR identified in a human gene core promoter) with the Old World monkeys and Apes and evidence of extreme "disease-only" genotypes at this STR with schizophrenia [14] provide the first link between a primate-specific STR and higher-order brain functions in human. The "exceptionally long" CA-repeat in the core promoter of $S C G B 2 B 2$ is another example of directional STR expansion in the Old World monkeys and Apes [5]. The PAXBP1 gene is an extreme example in which expansion of a core promoter CT-repeat occurs in the Old World monkeys and reaches maximum length and complexity in human; OMIM: 617621 [4].

As "exceptionally long" STRs may be subject to natural selection, short- and medium-size alleles ( $\geq 3$-repeats) might have had similar fate. This is indicated by the predominance of specific short- and medium-size pentaand hexanucleotide STRs and their cognate transcription factors (TFs) in the critical core promoter interval [15]. Indeed, shortening of a number of STRs and their identical co-occurrence is linked to the evolution of primates [8]. In line with the above findings, repeats associated with younger human TSSs tend to be shorter than those in older TSSs [10]. In the study reported here, we present genome-scale data on two categories of STRs, i. e., tri- and tetranucleotide STRs, and their implication in human evolution.

\section{Materials and methods}

The interval between -120 and +1 to the TSS of all human protein-coding genes annotated in the GeneCards database (version 3.0) (www.genecards.org) was screened for tri- and tetranucleotide STRs of $\geq 3$-repeats, based on the Ensembl database (versions 87-91) (asia.ensembl. org) and using the Microsatellite Repeats Finder at the following link: http://insilico.ehu.es/mini_tools/ microsatellites/

The evolutionary status of the identified STRs was analyzed in 25 species $(N)$, including primates $(N=5)$, non-primate mammals $(N=12)$, birds and reptiles $(N=5)$, amphibians $(N=1)$, and fish $(N=2)$, based on the Ensembl database.

Human specificity of transcripts was evaluated based on the multiple and pair-wise \%identity scoring of the TSS-flanking 5' untranslated region (UTR), using the sequence alignment program Clustal Omega (https://www. ebi.ac.uk/Tools/msa/clustalo), and the overall composition of the transcript and encoded protein (i.e., length of the transcript, number of exons and amino acids). The threshold of sequence identity was set at $50 \%$, which was based on the comparison of two randomly selected and unrelated sequences in the human genome.
The $p$ value for the skewing of the human-specific STR compartment was calculated using Levene's equality of variances test.

The $p$ values for transcript enrichment were calculated using the two by two table analysis;

the human-specific tri- and tetranucleotide STR groups were compared against corresponding randomly selected STRs from the non-human-specific STRs. The comparison was set based on the sample size of the human-specific STRs $(n)$ and the sample size of the non-human compartments (1.5n).

\section{Results}

Overall prevalence of tri- and tetranucleotide STR motifs across human protein-coding core promoter sequences

In total, 56 and 82 STR motifs were detected for the triand tetranucleotide repeats, respectively (Figs. 1 and 2). The most prevalent tri- and tetranucleotide STR motifs across the human protein-coding gene core promoters were GGC and GGGC, respectively (Figs. 1 and 2). In the category of non-GC STRs, GGA and TCCC were the most prevalent tri- and tetranucleotides, respectively.

\section{Skewing of the human-specific core promoter tri- and tetranucleotide STRs}

A significant skewing of the tri- and tetranucleotide STR distribution was found in the human-specific tri(Fig. 1) and tetranucleotide (Fig. 2) compartments (Levene's $p<0.001$ ). While the most prevalent tri- and tetranucleotide repeats in the non-human-specific category were the GGC- and GGGC-repeats, respectively, the most prevalent human-specific STRs were of the GCC and CTCC motifs, respectively. Disproportionate distribution of human-specific STRs was also detected in other STRs such as CCT, GAA, CTCC, GTTT, and GAAA.

The human-specific tri- and tetranucleotide STRs were of a wide range of motifs, e.g., the CCA motif in $A D C Y 6$, the TCCC motif in ARHGEF35, GCCC in DRD2, and GTTT in MCTP2 (Tables 1 and 2).

In a number of instances, not only the STR, but also the genes containing those STRs, were human-specific (e.g., ARHGEF35, AMY1C, and C1orf204). Furthermore, a number of the tri- and tetranucleotide STRs were found to be unique to the human species at the specified interval of -120 to +1 TSS. For example, in the tetranucleotide compartment, CACC, GACA, CCGG, GATA, TCTG, GGCT, and TTTA STRs were detected in human only.

\section{Enrichment of human-specific transcripts at the human- specific STR compartment}

Based on sequence comparison and the overall composition of the transcript and encoded protein, 25 


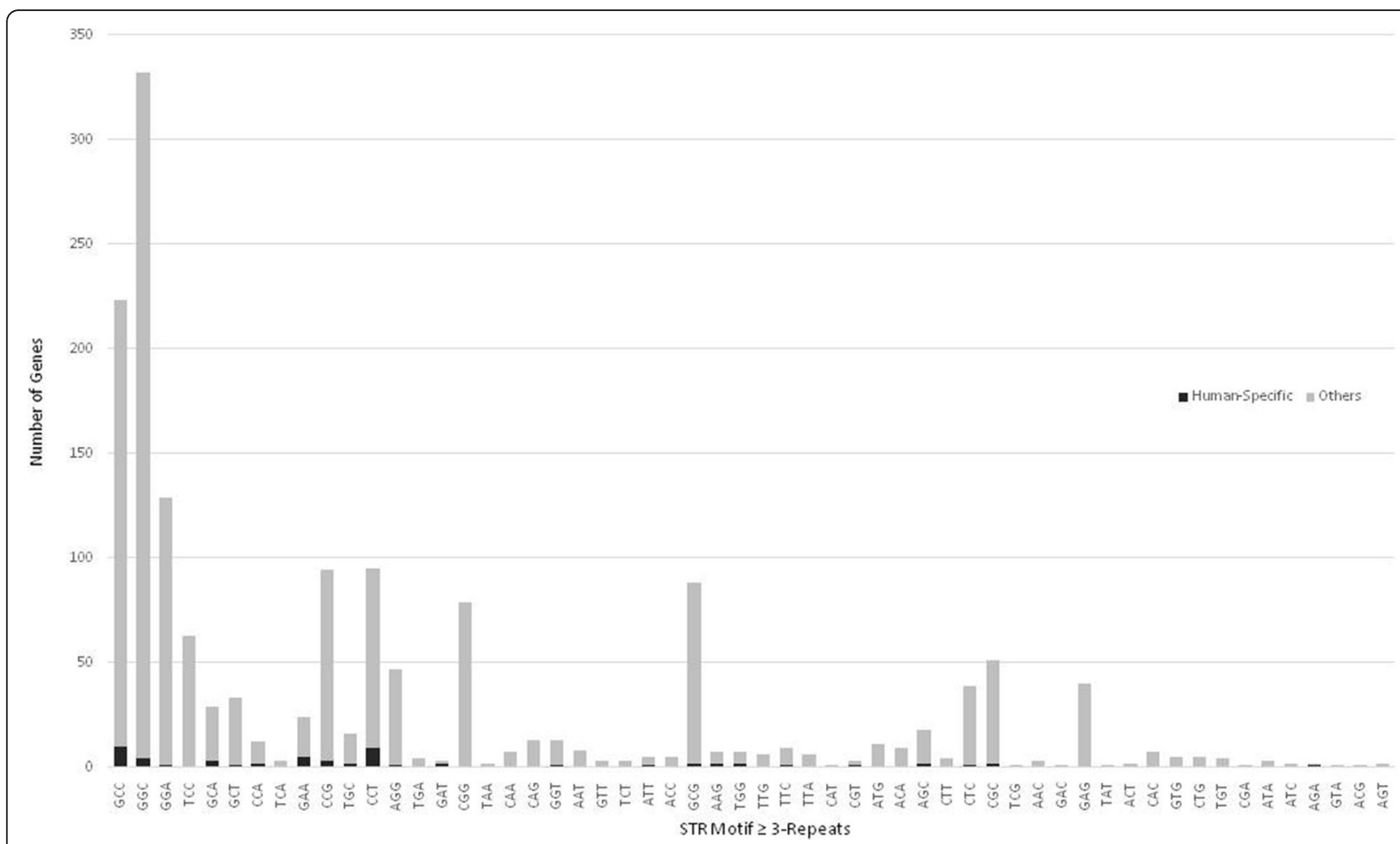

Fig. 1 Genome-scale prevalence of human protein-coding core promoter trinucleotide STRs and significant skewing of the human-specific STR compartment

and $26 \%$ of the transcripts in the tri and tetra human-specific compartments were found to be human-specific (mid- $p<0.00002$ and $\operatorname{mid}-p<0.002$ ), respectively). The \%identity score of multiple sequence alignment for the human-specific transcripts was 0 (exemplified in Fig. 3), and pair-wise analysis (exemplified in Fig. 4) resulted in \%identity scores ranging from 37 to $48 \%$. In the trinucleotide category, 14 genes, MPRIP, NPAS1, PAQR9, PRSS1, R3HDM2, TMEM99, ZSCAN30, C22orf24, ECSCR, AMY1C, DDX58, C1orf204, RGPD6, and LCE2B, contained human-specific transcripts. In the tetranucleotide category, five genes, DRD2, DUX4, TEAD4, ARL17B, and $A R H G E F 35$, contained human-specific transcripts.

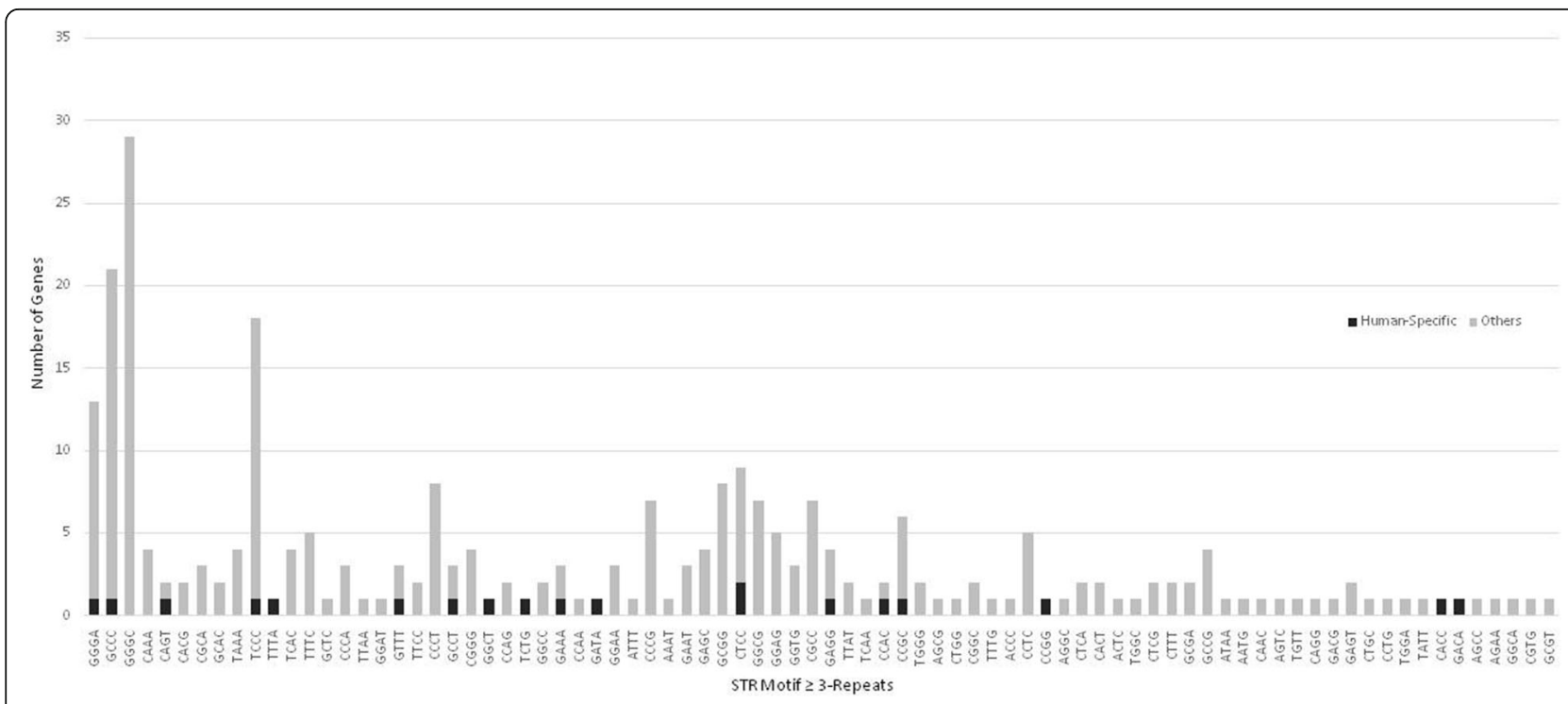

Fig. 2 Genome-scale prevalence of human protein-coding core promoter tetranucleotide STRs and significant skewing of the human-specific STR compartment 
Table 1 Genome-scale human-specific core promoter trinucleotide STRS

\begin{tabular}{|c|c|c|c|c|}
\hline Human gene symbol & Ensembl transcript ID & Variant no. & STR formula & \\
\hline$A D C Y 6$ & ENST00000307885.4 & 201 & $-48(C C A) 3$ & \\
\hline AMYIC & ENST00000370079.3 & 201 & - 79 (АТT)3 & \\
\hline$A P B B 1$ & ENST00000311051.7 & 202 & $-11(\mathrm{GCC}) 3$ & \\
\hline BRINP2 (FAM5B) & ENST00000361539.4 & 201 & $-26(\mathrm{GGC}) 5$ & \\
\hline BVES & ENST00000446408.2 & 203 & $-35(C C T) 3$ & \\
\hline CCDC178 (C18orf34) & ENST00000300227.12 & 201 & -79 (AGC)3 & -57 (CGC)5 \\
\hline $\mathrm{CDH} 4$ & ENST00000543233.2 & 201 & $-31(\mathrm{CCT}) 3$ & \\
\hline CIAPIN1 & ENST00000563341.1 & 202 & $-39(\mathrm{CCT}) 3$ & \\
\hline CNTNAP2 & ENST00000361727.7 & 201 & - $98(\mathrm{TGC}) 3$ & \\
\hline CST4 & ENST00000217423.3 & 201 & $-83(G G A) 3$ & \\
\hline CYP4A11 & ENST00000310638.8 & 201 & $-86(C C T) 3$ & \\
\hline Clorf204 & ENST00000368102.5 & 201 & $-11(\mathrm{AAG}) 3$ & \\
\hline C22orf24 & NM_015372.2.1 & & $-98(G C A) 3$ & \\
\hline C $3 A R 1$ & ENST00000546241.1 & 202 & $-70(A G A) 3$ & \\
\hline DDX58 & ENST00000379868.5 & 201 & $-33(\mathrm{CCT}) 3$ & \\
\hline$E C S C R$ & NM_001077693.3.1 & & $-121(\mathrm{CCA}) 3$ & \\
\hline GRIN2D & ENST00000263269.3 & 201 & - 67 (GCC)3 & \\
\hline GSDMB & ENST00000394175.6 & 203 & $-55(\mathrm{GGC}) 3$ & \\
\hline INPP4B & ENST00000503927.5 & 202 & $-88(C G C) 3$ & \\
\hline KBTBD12 & ENST00000407609.7 & 204 & $-57(\mathrm{CCT}) 3$ & \\
\hline KIAA1211 & ENST00000504228.5 & 203 & $-81(A A G) 3$ & \\
\hline KRAS & ENST00000311936.7 & 202 & $-89(G A A) 3$ & \\
\hline KTN1 & ENST00000395308.5 & 202 & -70 (GCG)9 & \\
\hline LACTBL1 & ENST00000426928.6 & 201 & $-58(G A A) 3$ & \\
\hline$\angle C E 2 B$ & ENST00000368780.3 & 201 & $-79(\mathrm{CCT}) 3$ & \\
\hline LCOR (C10orf12) & ENST00000356016.7 & 202 & $-97(C C T) 3$ & -108 (GCC)3 \\
\hline MPRIP & ENST00000466186.2 & 209 & $-88(\mathrm{GCA}) 11$ & \\
\hline MSANTD3 (C9orf30) & ENST00000374885.5 & 201 & $-25(\mathrm{GCC}) 7$ & \\
\hline NPAS1 & ENST00000439365.6 & 201 & -135 (GAA)9 & \\
\hline OR4X1 & ENST00000320048.1 & 201 & -100 (GAT)3 & \\
\hline$P A B P C 1 L 2 B$ & ENST00000373521.3 & 201 & $-60(\mathrm{GCC}) 3$ & \\
\hline PAQR9 & ENST00000498470.1 & 203 & $-29(\mathrm{TGC}) 3$ & \\
\hline PRSS1 & ENST00000492062.1 & 205 & $-96(\mathrm{GAT}) 3$ & \\
\hline RGPD6 & ENST00000455695.1 & 205 & $-70(\mathrm{GGC}) 5$ & \\
\hline RNF215 & ENST00000215798.10 & 201 & -123 (GCT)5 & \\
\hline R3HDM2 & ENST00000448732.1 & 208 & -27 (GCC)3 & \\
\hline SCN3B & ENST00000299333.7 & 201 & -29 (GGT)3 & \\
\hline SERPINB9 & ENST00000380698.4 & 201 & $-12(\mathrm{GCA}) 3$ & \\
\hline SIGLEC7 & ENST00000305628.7 & 201 & -80 (ТTC)3 & \\
\hline SPATC1L (C21orf56) & ENST00000330205.10 & 202 & -37 (TGG)4 & $-90(\mathrm{TGG}) 4$ \\
\hline STUB1 & ENST00000219548.8 & 201 & $-91(\mathrm{GCC}) 3$ & \\
\hline SUMF1 & ENST00000272902.9 & 201 & -102 (AGC)3 & \\
\hline TEX12 & ENST00000280358.4 & 201 & - 105 (TGG)3 & \\
\hline
\end{tabular}


Table 1 Genome-scale human-specific core promoter trinucleotide STRs (Continued)

\begin{tabular}{|c|c|c|c|c|}
\hline Human gene symbol & Ensembl transcript ID & Variant no. & STR formula & \\
\hline \multirow[t]{5}{*}{ TMEM99 } & ENST00000301665.7 & 201 & $-32(\mathrm{CCG}) 3$ & -47 (CCG)3 \\
\hline & & & -59 (CCG)3 & $-83(\mathrm{CCG}) 3$ \\
\hline & & & $-110(C C G) 3$ & $-125(\mathrm{CCG}) 3$ \\
\hline & & & $-48(\mathrm{GCC}) 3$ & $-60(\mathrm{GCC}) 3$ \\
\hline & & & $-84(\mathrm{GCC}) 3$ & $-126(\mathrm{GCC}) 3$ \\
\hline TNNC2 & ENST00000372557.1 & 202 & $-53(\mathrm{GCC}) 3$ & \\
\hline TPTE & ENST00000427445.6 & 201 & $-110(\mathrm{GCG}) 3$ & \\
\hline TRBJ2-7 & ENST00000390419.1 & 201 & $-120(\mathrm{GGC}) 3$ & \\
\hline TRGV5 & NC_000007.14:TRGV5:u_t_1.1 & & -48 (CTC)3 & \\
\hline TRIM39 & ENST00000376656.8 & 201 & $-58(\mathrm{CCT}) 4$ & \\
\hline UAP1 & ENST00000367926.8 & 204 & $-9(\mathrm{CGT}) 3$ & \\
\hline VNN2 & ENST00000326499.10 & 201 & $-31(\mathrm{GAA}) 10$ & \\
\hline WRN & NM_000553.4.1 & & $\begin{array}{l}-67(\mathrm{GCC}) 3 \\
-69(\mathrm{CCG}) 4\end{array}$ & $-92(\mathrm{GCC}) 3$ \\
\hline WRNIPI & ENST00000618555.4 & 205 & $-67(C C G) 3$ & \\
\hline ZDHHC21 & XM_006716760.1.1 & & $-32(A G G) 3$ & \\
\hline ZSCAN30 & ENST00000639929.1 & 212 & $-57(\mathrm{GAA}) 3$ & \\
\hline
\end{tabular}

The numbers before the brackets represent the start site of the STR in respect of the corresponding transcription start site. "Variant no" corresponds to the Ensembl isoform number

Table 2 Genome-scale human-specific core promoter tetranucleotide STRs

\begin{tabular}{|c|c|c|c|}
\hline Human gene symbol & Ensembl transcript ID & Variant no. & STR formula \\
\hline ARHGAP5 & ENST00000345122.7 & 202 & $-110(\mathrm{GGGA}) 4$ \\
\hline ARHGEF35 & ENST00000378115.2 & 201 & -22 (TCCC)3 \\
\hline$A R L 17 B$ & ENST00000622877.4 & 201 & - 99 (СТCC)3 \\
\hline ATP7A & ENST00000343533.9 & 201 & $-27(\mathrm{GAGG}) 3$ \\
\hline DRD2 & ENST00000542616.1 & 207 & -54 (GCCC)3 \\
\hline DUX4 & ENST00000565211.1 & 203 & - 144 (GGCT)6 \\
\hline FAM83G & ENST00000388995.10 & 202 & -80 (TCTG)3 \\
\hline GTF2IRD2B & ENST00000614064.4 & 206 & -17 (GAAA)3 \\
\hline$J C A D(K I A A 1462)$ & ENST00000375377.1 & 201 & -13 (CCGG)3 \\
\hline MCTP2 & ENST00000451018.7 & 203 & -102 (GTT)3 \\
\hline METTL21C (C13orf39) & ENST00000267273.6 & 201 & -69 (CAGT)3 \\
\hline OR10G6 & ENST00000307002.3 & 201 & -123 (GATA) 13 \\
\hline PHYHD1 & ENST00000308941.9 & 201 & - 107 (TTTA)3 \\
\hline SAMD1 & ENST00000269724.5 & 201 & -75 (CCGC)3 \\
\hline TEAD4 & ENST00000540314.1 & 206 & -51 (CTCC)3 \\
\hline TRAJ49 & ENST00000390488.1 & 201 & -124 (GCCT)7 \\
\hline$T R D J 2$ & ENST00000390475.1 & 201 & -86 (CCAC)3 \\
\hline TRAV38-1 & ENST00000390464.2 & 201 & -109 (CACC)3 \\
\hline TRAV7 & ENST00000390429.3 & 201 & $-111(\mathrm{GACA}) 3$ \\
\hline
\end{tabular}

The numbers before the brackets represent the start site of the STR in respect of the corresponding transcription start site. "Variant no" corresponds to the Ensembl isoform number 


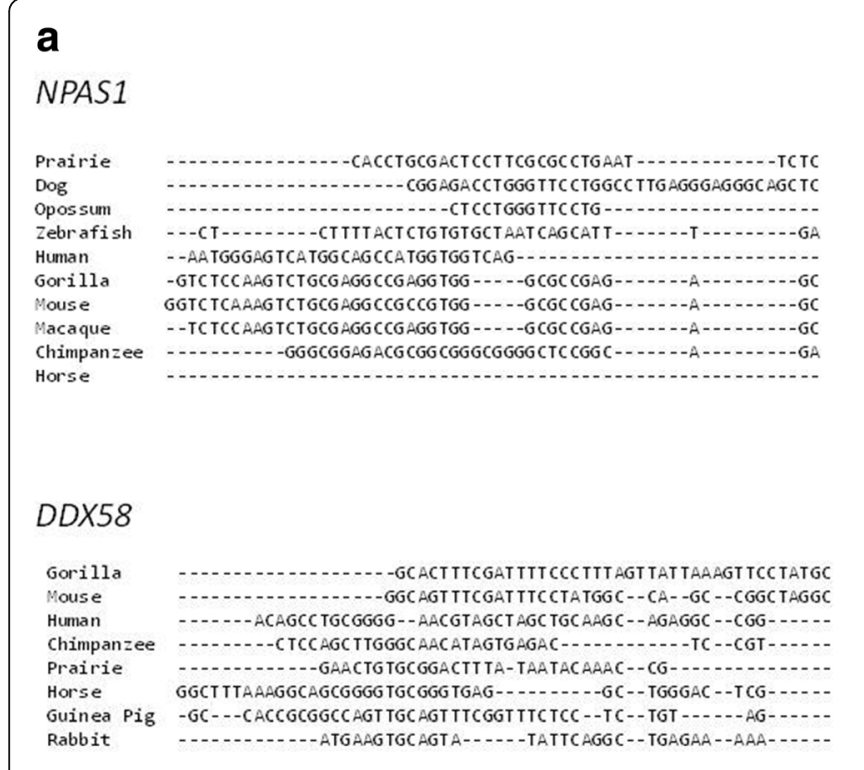

b

DRD2

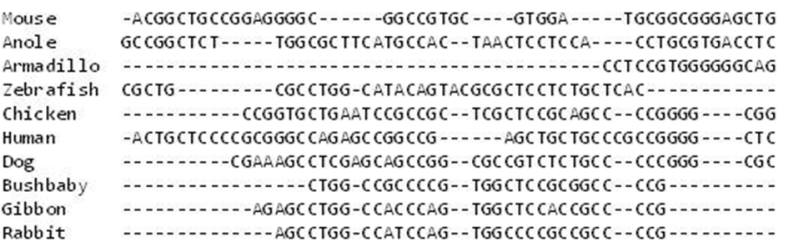

TEAD4

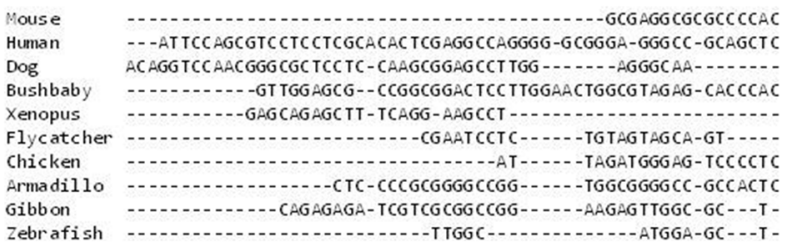

Fig. 3 Multiple sequence alignment of the TSS-flanking 5'UTRs. Examples of ClustAl Omega sequence alignment are represented in the tri- (a) and tetranucleotide (b) categories. Species inclusion was based on the information available in the Ensembl database
A number of the identified STRs were linked to noncanonical translation in the following genes, TEAD4, ECSCR, MPRIP, PAQR9, PRSS1, and ZSCAN30.

\section{Discussion}

There is an ever-growing literature on the biological and pathological implications of STRs at the interand intraspecies levels [16-27]. The STRs listed in the present study are genetic codes that are unique to humans and are likely to be responsible for the human-specific regulation of the relevant genes. The significant enrichment of human-specific transcripts at the human-specific STR compartment indicates a link to a mechanism for TSS selection and transcript specificity.

A number of the identified STRs such as GTTT have established repressor activity $[6,28,29]$ and are differentially expanded in certain genes in the Old World

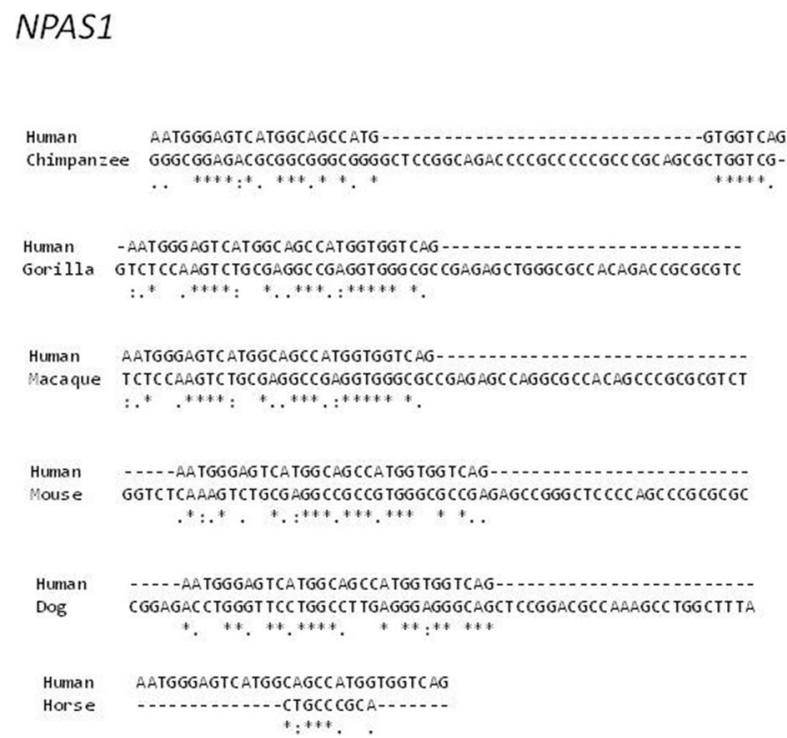

Fig. 4 Pair-wise sequence comparison of the TSS-flanking 5'UTRs. \%identity scoring was performed between human and other species. Asterisks represent sequence identity 
monkeys and Apes [14]. Purine STRs such as GAAA repeats are also functional in gene expression regulation, and their link to certain diseases unique to humans were previously reported [30, 31]. While the CG-rich STRs (e. g., CCG, GGGC) are subject to DNA methylation and can repress gene expression activity [32], they can also form G4 quadruplex structures, which have significant functions in gene expression regulation [33]. Several other identified STRs can form G4 structures with high overlap fraction (e.g., AGGG/CCCT, GCCC/GGGC).

It is not possible to estimate the number of crucial events that have led to the emergence of the human species. However, only a few genetic changes are needed to spur the evolution of new species in general, exemplified by the highly restricted initial divergence in butterfly hybridization models [34]. Accelerated evolution of a number of the identified genes in the present study (e.g., DRD2) has a well-established role in the origin of Homo sapiens [35]. Remarkably, a human-specific 7-amino acid transcript of this gene is flanked by a human-specific GCCC-repeat. Human-specific transcripts are increasingly recognized of having a role in the pathogenesis of diseases unique to the human species, such as schizophrenia $[25,36]$.

In a number of instances, not only the STR and the transcript, but also the gene containing these STRs and transcripts, were unique to humans, e.g., $A M Y 1 C$, which is indicated in the evolution of the human phenotype during the Pleistocene [37].

For a number of the identified genes, sparse literature is available on the relevant function and pathways (e.g., $A R H$ GEF35, CXorf40A, C22orf24, TMEM99, and ARL17B).

In a number of the identified genes, the STRs were linked to noncanonical (non-AUG) translation. Although the significance of this compartment is unknown for the most part, recent emerging data indicates likely biological functions [38].

The plasticity of STRs confers them unique ability to respond to adaptive evolutionary processes in a more efficient way than the quaternary codes provided by the SNSs. This potential aspect of STRs is vastly unknown at present, and it is expected that identification of STRs that have evolved differentially in humans vs. other species may pave the way for better understanding of the evolutionary implication of these highly mutable motifs.

This study warrants expansion to other vitally important gene regulatory sequences such as the distal promoter, 5'UTR, and 3'UTR. It is also necessary to sequence these STRs in characteristics and diseases that are unique to the human species. The recent reports of mass STR analysis using CRISPR/Cas9 [39] make it particularly more feasible to investigate STRs in the context of human evolution.

\section{Conclusion}

Our findings provide the first evidence of genomescale skewing of STRs at a specific region of the human genome, and support a link between STRs and TSS selection/transcript specificity. The genes and STRs listed here may have a role in the divergence of humans from other species through the development of characteristics and phenotypes that are unique to the human species.

\section{Abbreviations \\ SNS: Single nucleotide substitution; STR: Short tandem repeat; \\ TF: Transcription factor; TSS: Transcription start site; UTR: Untranslated region}

\section{Funding}

This research was funded by the University of Social Welfare and Rehabilitation Sciences, Tehran, Iran.

\section{Availability of data and materials}

Please contact author for data requests.

\section{Authors' contributions}

NN, FA, and TAA carried out the bioinformatics studies. AD and RS were the advisors of the project and helped in coordination. MO conceived the study, designed the project, supervised the analysis and wrote the manuscript. All authors read and approved the final manuscript.

Ethics approval and consent to participate

Not applicable.

Consent for publication

Not applicable.

\section{Competing interests}

The authors declare that they have no competing interests.

\section{Publisher's Note}

Springer Nature remains neutral with regard to jurisdictional claims in published maps and institutional affiliations.

\section{Author details}

${ }^{1}$ Iranian Research Center on Aging, University of Social Welfare and Rehabilitation Sciences, Tehran, Iran. ${ }^{2}$ Department of Biostatistics, University of Social Welfare and Rehabilitation Sciences, Tehran, Iran.

Received: 19 December 2017 Accepted: 20 March 2018

Published online: 05 April 2018

\section{References}

1. Press MO, Carlson KD, Queitsch C. The overdue promise of short tandem repeat variation for heritability. Trends Genet. 2014;30(11):504-12.

2. King DG. Evolution of simple sequence repeats as mutable sites. Adv Exp Med Biol. 2012;769:10-25.

3. Ohadi M, Mohammadparast S, Darvish H. Evolutionary trend of exceptionally long human core promoter short tandem repeats. Gene. 2012; 507(1):61-7.

4. Mohammadparast S, Bayat H, Biglarian A, Ohadi M. Exceptional expansion and conservation of a CT-repeat complex in the core promoter of PAXBP1 in primates. Am J Primatol. 2014;76(8):747-56.

5. Nikkhah M, Rezazadeh M, Khorshid HK, Biglarian A, Ohadi M. An exceptionally long CA-repeat in the core promoter of SCGB2B2 links with the evolution of apes and Old World monkeys. Gene. 2016;576(1):109-14.

6. Rezazadeh M, Gharesouran J, Mirabzadeh A, Khorshid HK, Biglarian A, Ohadi M. A primate-specific functional GTTT-repeat in the core promoter of CYTH4 is linked to bipolar disorder in human. Prog Neuro-Psychopharmacol Biol Psychiatry. 2015;56:161-7. 
7. Namdar-Aligoodarzi P, Mohammadparast S, Zaker-Kandjani B, Kakroodi ST, Vesiehsari MJ, Ohadi M. Exceptionally long 5' UTR short tandem repeats specifically linked to primates. Gene. 2015;569(1):88-94.

8. Ohadi M, Valipour E, Ghadimi-Haddadan S, Namdar-Aligoodarzi P, Bagheri A, Kowsari A, et al. Core promoter short tandem repeats as evolutionary switch codes for primate speciation. Am J Primatol. 2015;77(1):34-43.

9. Sonay TB, Carvalho T, Robinson MD, Greminger MP, Krützen M, Comas D, et al. Tandem repeat variation in human and great ape populations and its impact on gene expression divergence. Genome Res. 2015;25(11):1591-9.

10. Li C, Lenhard B, Luscombe NM. Integrated analysis sheds light on evolutionary trajectories of young transcription start sites in the human genome. bioRxiv. 2017. https://doi.org/10.1101/192757.

11. Kramer M, Sponholz C, Slaba M, Wissuwa B, Claus RA, Menzel U, et al. Alternative 5'untranslated regions are involved in expression regulation of human heme oxygenase-1. PLoS One. 2013;8(10):e77224.

12. Li Y, Seidel K, Marschall P, Klein M, Hope A, Schacherl J, et al. A polymorphic microsatellite repeat within the ECE-1C promoter is involved in transcriptional start site determination, human evolution, and Alzheimer's disease. J Neurosci. 2012;32(47):16807-20.

13. Emamalizadeh B, Movafagh A, Darvish $H$, Kazeminasab S, Andarva M, Namdar-Aligoodarzi P, et al. The human RIT2 core promoter short tandem repeat predominant allele is species-specific in length: a selective advantage for human evolution? Mol Gen Genomics. 2017;292(3):611-7.

14. Khademi E, Alehabib E, Shandiz EE, Ahmadifard A, Andarva M, Jamshidi J, et al. Support for "disease-only" genotypes and excess of homozygosity at the CYTH4 primate-specific GTT-repeat in schizophrenia. Genet Test Mol Biomarkers. 2017;21(8):485-90.

15. Bushehri A, Barez MM, Mansouri S, Biglarian A, Ohadi M. Genome-wide identification of human-and primate-specific core promoter short tandem repeats. Gene. 2016;587(1):83-90.

16. Valipour E, Kowsari A, Bayat H, Banan M, Kazeminasab S, Mohammadparast $S$, et al. Polymorphic core promoter GA-repeats alter gene expression of the early embryonic developmental genes. Gene. 2013;531(2):175-9.

17. Heidari A, Fam ZNS, Esmaeilzadeh-Gharehdaghi E, Banan M, Hosseinkhani S, Mohammadparast S, et al. Core promoter STRs: novel mechanism for interindividual variation in gene expression in humans. Gene. 2012;492(1):195-8.

18. Bagshaw AT. Functional mechanisms of microsatellite DNA in eukaryotic genomes. Genome Biol Evol. 2017:9(9):2428-43.

19. Bagshaw AT, Horwood L, Fergusson DM, Gemmell NJ, Kennedy MA. Microsatellite polymorphisms associated with human behavioural and psychological phenotypes including a gene-environment interaction. BMC Med Genet. 2017;18(1):12.

20. Gymrek M, Willems T, Guilmatre A, Zeng H, Markus B, Georgiev S, et al. Abundant contribution of short tandem repeats to gene expression variation in humans. Nat Genet. 2016:48(1):22-9.

21. Hammock EA, Young LJ. Microsatellite instability generates diversity in brain and sociobehavioral traits. Science. 2005:308(5728):1630-4.

22. Carrat GR, Hu M, Nguyen-Tu M-S, Chabosseau P, Gaulton K, van de Bunt M, et al. Decreased STARD10 expression is associated with defective insulin secretion in humans and mice. Am J Hum Genet. 2017;100(2):238-56.

23. Abe H, Gemmell NJ. Evolutionary footprints of short tandem repeats in avian promoters. Sci Rep. 2016;6:19421.

24. Fondon JW, Hammock EA, Hannan AJ, King DG. Simple sequence repeats: genetic modulators of brain function and behavior. Trends Neurosci. 2008 31(7):328-34.

25. Alizadeh F, Bozorgmehr A, Tavakkoly-Bazzaz J, Ohadi M. Skewing of the genetic architecture at the ZMYM3 human-specific 5' UTR short tandem repeat in schizophrenia. Mol Gen Genomics. 2018; https://doi.org/10.1007/ s00438-018-1415-8.

26. Hannan AJ. Tandem repeats mediating genetic plasticity in health and disease. Nat Rev Genet. 2018; https://doi.org/10.1038/nrg.2017.115.

27. Watts PC, Kallio ER, Koskela E, Lonn E, Mappes T, Mokkonen M. Stabilizing selection on microsatellite allele length at arginine vasopressin 1a recepto and oxytocin receptor loci. Proc Biol Sci. 2017;284(1869):20171896. https:// doi.org/10.1098/rspb.2017.1896

28. Andrioli LPM, Vasisht V, Theodosopoulou E, Oberstein A, Small S. Anterior repression of a Drosophila stripe enhancer requires three position-specific mechanisms. Development. 2002;129(21):4931-40.

29. Andrioli LP, Oberstein AL, Corado MS, Yu D, Small S. Groucho-dependent repression by sloppy-paired 1 differentially positions anterior pair-rule stripes in the Drosophila embryo. Dev Biol. 2004;276(2):541-51.
30. Darvish H, Heidari A, Hosseinkhani S, Movafagh A, Khaligh A, Jamshidi J, et al. Biased homozygous haplotypes across the human caveolin 1 upstream purine complex in Parkinson's disease. J Mol Neurosci. 2013;51(2):389-93.

31. Heidari A, Hosseinkhani S, Talebi S, Meshkani R, Esmaeilzadeh-Gharedaghi E, Banan M, et al. Haplotypes across the human caveolin 1 gene upstream purine complex significantly alter gene expression: implication in neurodegenerative disorders. Gene. 2012;505(1):186-9.

32. Quilez J, Guilmatre A, Garg P, Highnam G, Gymrek M, Erlich Y, et al. Polymorphic tandem repeats within gene promoters act as modifiers of gene expression and DNA methylation in humans. Nucleic Acids Res. 2016; 44(8):3750-62.

33. Sawaya S, Bagshaw A, Buschiazzo E, Kumar P, Chowdhury S, Black MA, et al. Microsatellite tandem repeats are abundant in human promoters and are associated with regulatory elements. PLoS One. 2013;8(2):e54710.

34. Kronforst MR, Hansen ME, Crawford NG, Gallant JR, Zhang W, Kulathinal RJ, et al. Hybridization reveals the evolving genomic architecture of speciation. Cell Rep. 2013;5(3):666-77.

35. Dorus S, Vallender EJ, Evans PD, Anderson JR, Gilbert SL, Mahowald M, et al. Accelerated evolution of nervous system genes in the origin of Homo sapiens. Cell. 2004;119(7):1027-40.

36. Li M, Jaffe AE, Straub RE, Tao R, Shin JH, Wang Y, et al. A human-specific AS3MT isoform and BORCS7 are molecular risk factors in the 10q24. 32 schizophrenia-associated locus. Nat Med. 2016;22(6):649-56.

37. Hardy K, Brand-Miller J, Brown KD, Thomas MG, Copeland L. The importance of dietary carbohydrate in human evolution. Q Rev Biol. 2015;90(3):251-68.

38. Na CH, Barbhuiya MA, Kim MS, Verbruggen S, Eacker SM, Pletnikova O, Troncoso JC, Halushka MK, Menschaert G, Overall CM, Pandey A. Discovery of noncanonical translation initiation sites through mass spectrometric analysis of protein N termini. Genome Res. 2018;28(1):25-36.

39. Shin G, Grimes SM, Lee H, Lau BT, Xia LC, Ji HP. CRISPR-Cas9-targeted fragmentation and selective sequencing enable massively parallel microsatellite analysis. Nat Commun. 2017:8:14291.

\section{Submit your next manuscript to BioMed Central and we will help you at every step:}

- We accept pre-submission inquiries

- Our selector tool helps you to find the most relevant journal

- We provide round the clock customer support

- Convenient online submission

- Thorough peer review

- Inclusion in PubMed and all major indexing services

- Maximum visibility for your research

Submit your manuscript at www.biomedcentral.com/submit
) Biomed Central 